\title{
El impedimento del ejercicio del derecho a una relación directa y regular entre abuelos y nietos como causal de desheredación e indignidad*
}

\author{
Susana Espada Mallorquín**
}

\begin{abstract}
RESUMEN
Tras la Ley 20.680 se reconoce en el ordenamiento chileno el derecho de los menores y los abuelos a mantener una relación directa y regular entre sí. Se considera que esta reforma en el ámbito del Derecho de familia debería llevar consigo una reforma en el Derecho sucesorio tendente a reconocer la posibilidad de desheredación por impedir el ejercicio de este derecho e incluso su consideración como una causal de indignidad. De no llevarse a cabo la oportuna reforma legislativa, en el artículo se plantea la posibilidad de que por vía interpretativa los tribunales puedan considerar el impedimento del ejercicio de este derecho como una injuria grave del artículo 1208.1 CC a efectos de la desheredación, o como un supuesto del artículo 968.2 CC en el caso de la indignidad.
\end{abstract}

Derechos de los abuelos - desheredación - indignidad

\section{The impediment to the grandparents visitation right as an disinberitance and unworthiness ground}

\begin{abstract}
In accordance with the 20680 law, the Chilean legal system recognize the right of grandparents to maintain a direct and regular relationships with their grandchildrens. The author considers that this Family law reform should entail a reform in Inheritance law that provides for the possibility to recognise the disinheritance for hindering the exercise of this grandparents right and also this could be considerer as an unworthiness ground. Because of this lack of adequate legislative regulation, the article envisages the possibility of a jurisprudential interpretation that considers the impediment to the exercise of the grandparents visitation rights it is an injury ex article 1208.1 CC for the disinheritance or an unworthiness ground ex article 968.2 CC.
\end{abstract}

Grandparents visitation rights - disinheritance - unworthiness

* El presente artículo se desarrolla dentro del marco del Proyecto de Iniciación a la Investigación FONDECYT 11110204 relativo a "El Derecho sucesorio ante los cambios sociológicos y jurídicos de la familia chilena", del cual la autora es investigadora responsable. Agradezco a todos los profesores participantes en el Seminario de Profesores de Derecho civil la Universidad Autónoma de Madrid los comentarios que realizaron en la presentación del inicio de este trabajo en el transcurso de una estancia de investigación dentro del marco del citado Proyecto. Cualquier error es de mi exclusiva responsabilidad. Finalmente quiero dedicarle este artículo a mi maestro don José María Miquel González.

** Doctora en Derecho por la Universidad Autónoma de Madrid. Profesora de Derecho civil en la Universidad Adolfo Ibáñez. Correo electrónico: susana.espada@uai.cl.

Artículo recibido el 7 de enero de 2015 y aceptado para su publicación el 28 de agosto de 2015. 


\section{INTRODUCCIÓN}

Recientemente se ha reconocido en Chile el derecho de los menores a tener una relación directa y regular con sus abuelos. La Ley 20680 de 16 de junio de 2013 destinada a modificar el Código Civil y los distintos cuerpos legales con el objeto de proteger la integridad del menor ha modificado e incorporado un inciso segundo al artículo 229 del Código Civil (CC) donde se establece que: "El hijo tiene derecho a mantener una relación directa y regular con sus abuelos. A falta de acuerdo el juez fijará la modalidad de esta relación atendiendo el interés del hijo, en conformidad con los criterios del art. 229"1. Tras su modificación, en el inciso primero del citado artículo 229 CC se define una relación directa y regular como aquella que propende a que el vínculo familiar entre el padre o madre -y también ahora los abuelos- que no ejerce el cuidado personal y su hijo - nieto- se mantenga mediante un contacto periódico y estable. Se trata por lo tanto de una reforma legislativa que introduce un nuevo derecho en el ámbito del Derecho de familia, como es el derecho a mantener una relación personal, regular y estable entre los nietos y sus abuelos.

La hipótesis de trabajo de la que parte el presente artículo es que la citada reforma de Derecho de familia debería haber llevado aparejada una reforma en Derecho sucesorio tendente a reconocer la posibilidad de desheredación por incumplimiento de este derecho e incluso la consideración del impedimento del ejercicio legítimo del mismo como una causal de indignidad. Para poder sostener lo anterior es preciso, en primer lugar, reflexionar sobre algunas preguntas esenciales relativas básicamente a la naturaleza y fundamento del nuevo derecho de visita de los abuelos para, posteriormente, analizar la oportunidad de considerar el incumplimiento del citado derecho como una causal de indignidad o de justa desheredación.

\section{FUNDAMENTOS DEL DERECHO A UNA RELACIÓN DIRECTA Y REGULAR ENTRE NIETOS Y ABUELOS}

Debido a la hipótesis de trabajo del presente artículo, la primera pregunta que es posible plantearse es ante qué tipo de derecho nos encontramos y quiénes son los titulares del mismo.

\footnotetext{
${ }^{1}$ Según el artículo 229.1 CC: "Para la determinación de este régimen, los padres, o el juez en su caso, fomentarán una relación sana y cercana entre el padre o madre que no ejerce el cuidado personal y su hijo, velando por el interés superior de este último, su derecho a ser oído y la evolución de sus facultades, y considerando especialmente: a) La edad del hijo; b) La vinculación afectiva entre el hijo y su padre o madre, según corresponda, y la relación con sus parientes cercanos; c) El régimen de cuidado personal del hijo que se haya acordado o determinado; d) Cualquier otro elemento de relevancia en consideración al interés superior del hijo. Sea que se decrete judicialmente el régimen de relación directa y regular o en la aprobación de acuerdos de los padres en estas materias, el juez deberá asegurar la mayor participación y corresponsabilidad de estos en la vida del hijo, estableciendo las condiciones que fomenten una relación sana y cercana. El padre o madre que ejerza el cuidado personal del hijo no obstaculizará el régimen de relación directa y regular que se establezca a favor del otro padre, conforme a lo preceptuado en este artículo. Se suspenderá o restringirá el ejercicio de este derecho cuando manifiestamente perjudique el bienestar del hijo, lo que declarará el tribunal fundadamente".
} 


\section{Naturaleza jurídica del derecho de visitas entre abuelos y nietos}

Respecto de su naturaleza jurídica, el legislador chileno lo ha configurado no como una mera facultad, sino como un auténtico derecho a poder mantener relaciones personales entre abuelos y nietos. Derecho de carácter autónomo y extrapatrimonial que permite a sus titulares mantener relaciones entre sí, pudiendo exigir los medios necesarios para garantizar su cumplimiento ${ }^{2}$. Su ejercicio va a suponer un límite a la autoridad paterna de los progenitores, pues tendrán que soportarlo y posibilitarlo; y sus titulares podrán acudir a los tribunales en los casos de falta de acuerdo respecto de la modalidad para llevarlo a cabo o para que proceda su legítima suspensión o denegación.

Precisando un poco más, considero que el nuevo artículo 229.2 CC contempla uno de los denominados derechos-deber que pretende satisfacer los intereses del menor y los de los abuelos. Se trata de un derecho que tiene en cuenta no solo el interés superior del menor sino que también pretende garantizar y proteger el derecho de los abuelos a la relación afectiva con sus nietos ${ }^{3}$. Igualmente es un deber, ya que en el caso de los abuelos estos están obligados a ejercitar dicho derecho respetando y persiguiendo siempre salvaguardar el interés superior del menor. Además, como derecho personal incluido dentro del ámbito de los derechos familiares, el derecho a mantener la relación directa y regular es un derecho que resulta inalienable, irrenunciable, imprescriptible y subordinado al interés del menor ${ }^{4}$.

\section{Los titulares del derecho}

Este derecho se enuncia en el artículo 229-2 CC como de titularidad del menor; sin embargo, lo cierto es que debido a la remisión que se realiza al párrafo primero del citado artículo 229 CC los abuelos "que no tienen el cuidado personal del menor tendrán el derecho y el deber de mantener con él una relación directa y regular (...)”. Por tanto es posible afirmar que a pesar de la redacción final del párrafo segundo, los abuelos también son titulares del derecho a la relación directa y regular con los nietos. Estaríamos ante un derecho recíproco en el sentido de que tanto abuelos como nietos tienen derecho a mantener una relación directa y regular entre sí. Además los abuelos

${ }^{2}$ En este punto, por ejemplo, en la doctrina francesa aunque se habla de prerrogativa, en realidad también se concibe como un verdadero derecho de la persona, vid. Ruz Lártiga, G., "El Derecho de visitas en Francia: un derecho de la persona en la búsqueda del justo equilibrio entre Derecho parental, interés del niño y prerrogativas de terceros", en Revista Chilena de Derecho de Familia, no 3, Santiago, 2010, pp. 139-162.

${ }^{3}$ En este sentido destacar, dentro de la doctrina española, a Carballo Fidalgo, M.; "El derecho de visita de los abuelos y la atribución de guarda de sus nietos tras la Ley 42/2003, de 21 de noviembre. Aspectos sustantivos y procesales", en Revista de Derecho de Familia, n 30, enero-marzo 2006, Madrid, p. 48; De Prada González, J. M.; "La patria potestad tras la reforma del Código Civil”, en Anales de la Academia Matritense $y$ del Notariado, t. XXV, 1982, Madrid, p. 389 o Gaya Sicilia, R.; "El derecho de los abuelos a relacionarse con los nietos”; en Anuario de Derecho civil, 2002-I, Madrid, p. 96.

${ }^{4}$ En idéntico sentido Díaz Alabart, S.; "El derecho de relación personal del menor y sus parientes y allegados (art. 160.2 CC)", en Revista de Derecho Privado, mayo-junio 2003, p. 354. 
están legitimados a participar en los acuerdos donde la determinación de dicho derecho se lleve a cabo, luego de estar interesados deberán concurrir al acuerdo de relación directa y regular para que en el mismo se regule el ejercicio de su derecho. También pueden reclamar judicialmente su cumplimiento.

En la tramitación de la Ley 20.680, aparte del menor, originariamente los titulares de este derecho a una relación directa y regular eran los parientes de forma general. En sede parlamentaria se estableció que la titularidad del derecho correspondía exclusivamente a los abuelos, pues se votó en contra de considerar beneficiarios a todos los ascendientes, ya que se quería expresamente reconocer la importancia de la relación de los abuelos con los nietos 5 .

En este punto considero oportuno criticar la regulación chilena por su carácter excesivamente restringido respecto de los titulares del mencionado derecho de visitas. Si lo que se buscaba con el reconocimiento expreso de este derecho era favorecer al menor en sus relaciones personales familiares más directas, no logro comprender qué inconveniente existía en haber contemplado a todos los ascendientes de resultar esta relación intergeneracional positiva para el interés del menor y por qué limitarlo solo a los abuelos. Además si lo que se quería era destacar la especialidad de la relación abuelo-nieto, quizás hubiera sido una buena opción establecer un orden de prelación que determinase que solo en ausencia de los abuelos le corresponderá dicho derecho a los demás ascendientes, pero no directamente excluir al resto de ascendientes como posibles titulares del derecho de visita ${ }^{6}$.

Igualmente, considero que dentro de los posibles titulares de este derecho se debería haber contemplado una figura más flexible que admitiese la posibilidad de reconocimiento en favor de los denominados padres y madres afectivos, es decir, los convivientes de hecho que se relacionan con los hijos anteriores de sus parejas de hecho. Estos convivientes en la actualidad carecen de cualquier reconocimiento respecto de esta posibilidad de mantener una relación directa y regular con los menores con los que lógicamente puede que hayan mantenido una relación afectiva y doméstica durante muchos años antes de la crisis o del fallecimiento de la pareja ${ }^{7}$.

${ }^{5}$ La introducción del inciso segundo del artículo 229 en la tramitación parlamentaria se realiza en el segundo informe de la Comisión de Constitución (p. 538 de la Historia de la Ley 20.680). Posteriormente el debate parlamentario donde se aborda esta cuestión y que culmina con la sustitución de "ascendiente" por “abuelos" se puede consultar en las pp. 544-577, 673, 681 y 701 de la historia de la Ley 20.680, www.ley.cl

${ }^{6}$ En otros ordenamientos los legisladores han optado por un reconocimiento más amplio de este derecho de visitas. Así se puede destacar el caso francés, cuyo artículo 371-4 Code civil establece que el hijo tiene derecho a mantener relaciones personales con sus ascendientes. Por su parte, en Italia, el artículo 155 del Codice en su inciso primero reconoce el derecho a conservar relaciones significativas con los ascendientes y con los parientes de cada uno de los padres. En Alemania, el parágrafo primero del 1685 BGB otorga este derecho a abuelos y hermanos, cónyuges y anteriores cónyuges de uno de los padres que hayan vivido en comunidad doméstica y a personas bajo cuyo cuidado familiar el menor hubiera permanecido durante cierto tiempo. Y, finalmente, en España se establece en el artículo 160 CC que no se podrán impedir sin justa causa las relaciones personales entre el hijo y otros parientes y allegados.

${ }^{7}$ Tangencialmente el legislador se ha hecho cargo de dicha circunstancia en el recientemente aprobado Proyecto de ley de Acuerdos de Unión Civil, ya que en los casos de inhabilidad moral o física de ambos 


\section{El fundamento del derecho de visitas entre nietos y abuelos}

Este derecho de relación directa y regular entre los abuelos y los nietos tiene su fundamento en que se considera que el contacto periódico y estable entre ellos es beneficioso para el desarrollo de la personalidad del menor y permite garantizar la cohesión y la transmisión de los valores familiares. El reconocimiento expreso de este derecho de relación entre abuelos y nietos constituye una reforma en el ámbito del Derecho de familia que protege en mayor medida los intereses de los menores haciéndose cargo de la realidad sociológica y cultural actual y que, a su vez, garantiza el desarrollo de las relaciones familiares intergeneracionales ${ }^{8}$.

Desde una perspectiva de política legislativa el reconocimiento del derecho de visita a los abuelos es una muestra de una tendencia destinada a otorgar una mayor protección y reconocimiento a este sector de la población cada vez más numeroso9 . Además, sociológicamente, a nivel cultural y familiar, los abuelos representan cada vez más un papel esencial dentro del ámbito familiar, básicamente como cuidadores de sus nietos ante las crecientes necesidades laborales de los padres siendo protagonistas directos en el proceso de socialización de los menores ${ }^{10}$. Esto genera estrechos vínculos de afectividad que favorecen el desarrollo de la personalidad del menor, lo que justifica la necesidad de garantizar su protección en situaciones de crisis familiar donde puede verse afectado el normal desarrollo de esta relación.

Por tanto, el fundamento del derecho a una relación directa y regular entre abuelos y nietos es proteger el interés del menor en su desarrollo personal, para lo que se considera relevante la posibilidad de mantener relaciones personales y afectivas entre los nietos y sus abuelos, como parientes más directos en la vida familiar. El reconocimiento expreso de este derecho busca garantizar el beneficio que en su desarrollo integral como persona tiene para un nieto la posibilidad de mantener una relación directa y regular con sus abuelos ${ }^{11}$. Si bien existen lazos de parentesco, lo que se presume iuris tantum es el cariño y afecto en esta relación intergeneracional que contribuye al pleno desarrollo de los niños, pero también de los abuelos. Lógicamente, todas estas afirmaciones parten

padres, el juez puede preferir al conviviente civil para el cuidado personal de los hijos (art. 45 del Proyecto que modifica el art. $226 \mathrm{CC}$ ). Sin embargo, esto no contempla todas las circunstancias posibles respecto de los convivientes civiles (los firmantes de estos acuerdos) y, por supuesto, deja plenamente vigente la observación realizada respecto de la situación de los convivientes de hecho.

${ }^{8}$ Desde la psicología del desarrollo, en relación con el significado de los abuelos y su aporte positivo en la relación con los nietos, entre otros, vid. Kail Robert V. y Cavanaugh John C., Desarrollo humano. Una perspectiva del ciclo vital, 5 ed., Cengage Learning, México, 2011, pp. 499-502.

${ }^{9}$ En Chile, si observamos los resultados publicados por el Instituto Nacional de Estadística desde el 2006 al 2012 se observa un progresivo envejecimiento de la población, donde más del 50\% de la misma está entre los 60 y los 79 años de edad.

${ }^{10}$ Destacar el estudio sociojurídico realizado por García Ibáñez en el marco europeo; García Ibáñez, J. "El derecho a las relaciones personales entre nietos y abuelos. Una aproximación sociojurídica", en REDUR 10, diciembre 2012, pp. 105-122.

${ }^{11}$ En este sentido podemos destacar en el ámbito europeo la Sentencia del Tribunal Europeo de Derechos Humanos, sección 3, caso Amanalachioai contra Rumanía de 26 de mayo de 2009 (TEDH 2009/59). 
de la premisa de que esta relación intergeneracional deberá mantenerse siempre que el interés del menor lo justifique.

\section{Contenido del derecho de visitas}

Como ya se mencionó, en el artículo 229 CC se han definido estas relaciones como aquellas que buscan que el vínculo familiar entre nietos y abuelos que no ejercen su cuidado personal se mantenga por medio de un contacto periódico y estable dentro de una relación sana y cercana. En la práctica qué se entienda por un contacto periódico y estable es un concepto jurídico indeterminado cuyo contenido específico deberá de ser precisado por los interesados en cada acuerdo en concreto o por el juez en los casos conflictivos; al igual que el tiempo, modo y lugar de ejercicio, teniendo siempre como marco esencial el principio del interés del menor ${ }^{12}$. Eso sí el ejercicio de este derecho implicaría por ejemplo la obligación de recoger y entregar al menor en el lugar determinado por las partes o por el juez, la obligación de cuidar al nieto mientras se desarrolle la visita, dándole sustento o vigilando su salud e integridad física ${ }^{13}$.

El ejercicio de este derecho a las relaciones intergeneracionales puede verse afectado en los casos de crisis por el divorcio, separación o nulidad matrimonial de los padres, donde la atribución de la autoridad paterna a un progenitor puede impedir a los ascendientes del otro progenitor que se relacionen con su nieto. Asimismo pueden peligrar estas relaciones en los casos de fallecimiento de uno de los cónyuges, si el sobreviviente pone trabas a la relación; y también por la existencia de malas relaciones entre hijos y padres que llevan a impedir o distanciar la relación de abuelos y nietos ${ }^{14}$.

En este sentido, creo que en los casos de crisis matrimoniales el derecho de relación directa y regular entre abuelos y nietos en extensión y periodicidad debería ser más reducido que el que se les otorga habitualmente a los progenitores, a causa de la más que probable colisión con los derechos del padre separado, anulado o divorciado ${ }^{15}$. Esta menor extensión y periodicidad se justificaría porque la vinculación de los hijos con los abuelos es menor a la que por regla general existe con los padres. Por lo demás, en los casos de fallecimiento de uno de los progenitores, los padres del fallecido pueden

12 En España, la doctrina entiende que dicha relación comprende la conexión, correspondencia, trato, comunicación de una persona a otra, en la que cabe entender incluidas las estancias del menor durante cierto tiempo en el hogar de los abuelos, vid. entre otros Lete del Río, J.M.; "El derecho de visitas de los abuelos", en Poder Judicial, no 25, marzo 1992, p. 149.

${ }^{13}$ En otros ordenamientos lo que parece evidente que queda fuera del contenido de este derecho de visita son las funciones educativas que le corresponden a los progenitores. Es evidente que derivado de la relación, los abuelos van a poder ejercer cierta influencia sobre los nietos, pero eso no les legitima al amparo de este derecho para determinar la educación de los nietos, vid. García Ibáñez, J. op. cit., pp. 117-118.

${ }^{14}$ Berrocal Lanzarot, A.I.; "Derecho de visitas de los abuelos. A propósito de la STS de 20 de octubre de 2011", en Revista Crítica de Derecho Inmobiliario, n 730, p. 1006.

${ }^{15}$ Prosiguiendo con el ejemplo del caso español, la jurisprudencia en estos casos suele por regla general otorgar al derecho de visitas de los abuelos una tercera parte del tiempo que de ordinario establece en favor del padre no custodio; vid. Berrocal Lanzarot, A.I.; op. cit., pp. 1013-1014. 
tener un derecho con un contenido más amplio, ya que no existe en principio una colisión con los derechos del padre separado o divorciado y, además, esta relación sirve como garantía de la transmisión de los valores familiares que en vida hubiera asumido el progenitor fallecido, especialmente cuando del contacto con los abuelos dependa el mantenimiento del menor de las relaciones con el resto de parientes de esa misma línea familiar (tíos, primos... $)^{16}$.

Este derecho de relación personal entre abuelos y nietos, al igual que sucede respecto de los progenitores, puede suspenderse o restringirse cuando un tribunal determine que de forma manifiesta se perjudica el bienestar del hijo (art. 229 in fine CC). Por tanto, legalmente existe una presunción iuris tantum del bienestar del menor a consecuencia del mantenimiento de las relaciones con los abuelos. Quien considere dicha relación perjudicial podrá impedir el ejercicio de dicho derecho, pero deberá probar que la relación intergeneracional causa un perjuicio al menor en el caso concreto.

En la regulación no se contempla un listado de causas por las que dicho derecho podría suspenderse. Si acudimos a otros ordenamientos podemos observar cómo, por ejemplo, en la doctrina española se han considerado como justas causas para dicha suspensión la existencia de malos tratos, las malas relaciones entre abuelos y nietos, el deliberado ánimo de los abuelos de influir en aspectos relativos a la patria potestad (educación de los menores), la enfermedad mental de los abuelos, el peligro de que el contacto con los abuelos impida la recuperación psicológica del nieto en casos de fallecimiento de alguno de los progenitores, el incumplimiento por parte de los abuelos de medidas de alejamiento en relación con su hijo en casos de violencia familiar, la negativa de alimentos al nieto, la intromisión negativa en la vida familiar (siendo los abuelos los causantes de crisis matrimonial). Sin embargo, no serían justas causas, por ejemplo, la sola opinión del guardador respecto de la mala influencia de las visitas de los abuelos para el menor, las malas relaciones o desavenencias entre el progenitor y los abuelos que solo se tendrían en cuenta si llegaran a desestabilizar al menor, la sola voluntad contraria del menor a la relación con sus abuelos o el divorcio o nuevo matrimonio de los abuelos ${ }^{17}$.

\section{Fundamentos de las CAUSALES DE INDignidAd y DE DESHEREDACión}

Lo expuesto anteriormente pone en evidencia una realidad y es que los principios de Derecho de familia y las normas de convivencia familiar han sustituido algunos criterios por otros parámetros normativos y realidades sociales que plantean nuevos retos en el ámbito del Derecho sucesorio. Es por ello que quiero reiterar que este nuevo derecho a mantener una relación directa y regular entre los nietos y abuelos que se acaba de

\footnotetext{
${ }^{16}$ Berrocal Lanzarot, A. I.; op. cit., pp. 1015-1016.

${ }^{17}$ Colás Escadón, A.; Relaciones familiares de los nietos con los abuelos: derecho de visitas, estancia, comunicación $y$ atribución de guarda y custodia (Ley 42/2003), Thomson Aranzadi, 2005, Navarra, pp. 141-155 y Salanova Villanueva, M. "Notas sobre el derecho de los abuelos a mantener relaciones personales con sus nietos", en Anuario de Derecho civil, 1996-I, pp. 952-958.
} 
analizar, suscita una necesaria reflexión dentro de la regulación de las exclusiones de la herencia en el ámbito del Derecho sucesorio. Adelantando una idea que posteriormente se desarrollará, a mi juicio, en Chile sería necesaria y conveniente una reforma legal en el ámbito de Derecho sucesorio destinada a mejorar la regulación de las exclusiones de la herencia, por un lado haciéndolas más acorde con la realidad sociológica y familiar actual y, por otro, más coherentes con los cambios que en el ámbito de Derecho de familia se han llevado a cabo y que pueden repercutir de forma significativa en esta materia.

Para poder fundamentar esta afirmación hay que plantearse ciertas preguntas en materia sucesoria. En primer lugar es preciso tener en cuenta cuál es el fundamento de las dos principales instituciones destinadas a la exclusión del reconocimiento de derechos sucesorios, esto es, la desheredación y la indignidad. Y posteriormente analizar qué tipo de conductas se contemplan en las causales de ambas instituciones.

\section{Fundamento de la desheredación}

La desheredación es una figura propia de ordenamientos, como el chileno, donde la libertad de testar está limitada por la existencia de asignatarios forzosos. En esos sistemas tan solo por las causas legales debidamente acreditadas va a ser posible privar de sus derechos legítimos a los asignatarios forzosos. En el artículo 1207 CC se define el desheredamiento como una disposición testamentaria por la que se ordena que un legitimario sea privado de todo o parte de su legítima ${ }^{18}$. La protección que el legislador otorga a los asignatarios forzosos parte de la presunción de que estos van a tener una conducta acorde con los cercanos lazos familiares que le unen con el causante basados en un respeto recíproco y es dicho respeto lo que justifica la atribución patrimonial ${ }^{19}$. Es por ello que cuando estos cánones de conducta se violan de forma grave, la ley autoriza al causante a privar a los legitimarios de su asignación legal.

Es importante destacar que esta fundamentación de la desheredación tiene presente la faceta familiar del contenido del derecho a la herencia, donde no solo se considera la libertad de testar, sino también el derecho a heredar de los parientes ${ }^{20}$. En mi opinión el constituyente reconoce el derecho a la propiedad, pero al mismo tiempo tiene el deber de proteger y fortalecer la institución de la familia (art. 1 CPE). Por tanto, aunque es evidente que el fundamento del derecho a la sucesión está vinculado al derecho de propiedad y a la necesidad de perpetuar los patrimonios después del fallecimiento de sus titulares, creo que no es menos cierto que el fundamento de esta necesidad se basa

${ }^{18}$ Rodríguez Grez completa esta definición señalando que la desheredación es el medio del que dispone el causante para privar a sus herederos forzosos legitimarios de la asignación que les corresponde, cuando han incurrido en una causa justificada por la ley que lo permite y siempre que sea probada judicialmente en vida del causante o después de la muerte por los interesados, vid. Rodríguez Grez, Instituciones de Derecho Sucesorio, vol. 2, Editorial Jurídica de Chile, Santiago, 2002, p. 18.

${ }^{19}$ Elorriaga de Bonis, F.; Derecho Sucesorio, Abeledo Perrot, Santiago, 2010, p. 487.

${ }^{20}$ Algaba Ros, S.; Efectos de la desheredación, Tirant monografías, Valencia, 2002, p. 116. 
también en cuestiones de índole sociofamiliar ${ }^{21}$. Considero que existe una vertiente familiar en el Derecho sucesorio que parte de la función de la familia como un elemento configurador de la sociedad y la necesidad de admitir la transmisión del patrimonio familiar como un medio de garantía y defensa de la continuidad de la misma.

Es por ello que en virtud de los importantes efectos que siguen a la desheredación, la forma de llevarla a cabo necesariamente debe ser mediante testamento (art. 1207.1 CC) y solo por alguna de las causas taxativas que se contemplan en el artículo 1208 CC. Dichas causales deben expresarse específicamente en el testamento e, igualmente, es necesario acreditar los hechos que las constituyen en juicio en vida del testador o después de su fallecimiento. Excepcionalmente no es necesario probar los hechos constitutivos de la causal de desheredamiento cuando "el desheredado no reclame su legítima dentro de los cuatro años subsiguientes a la apertura de la sucesión, o de los cuatro años contados desde el día en que haya cesado su incapacidad de administrar si al tiempo de abrirse la sucesión era incapaz" (art. $\left.1209.2^{\circ} \mathrm{CC}\right)^{22}$.

A pesar de lo anterior, considero oportuno adelantar una idea que se desarrollará posteriormente y es que el hecho de que se establezca el carácter taxativo de las causales de desheredación no significa, como se ha llegado a afirmar, que estas causales no puedan interpretarse acogiendo situaciones análogas a las contempladas; por el contrario, considero que lo que implica el carácter taxativo de las cláusulas es que el juez podrá interpretarlas, pero de manera restrictiva, adecuándola al tiempo y a la realidad social actual en la que se aplica, sin que ello esté expresamente prohibido ${ }^{23}$.

\section{Fundamento de la indignidad}

En lo que respecta a la indignidad, su fundamento consiste en la falta de mérito de un sujeto para suceder al causante debido al incumplimiento de deberes que el potencial heredero tenía con el fallecido o porque dicho heredero faltó al respeto que su memoria le imponía. Es una sanción civil a aquel que ha cometido un hecho socialmente reprochable contra el fallecido, por tanto se entiende que, salvo su perdón (art. 973 CC), el sujeto que no ha sido leal al causante en vida no es digno de sucederle tras su muerte.

En el ordenamiento chileno existe una presunción de dignidad (art. 961 CC), por lo que para que la causal de indignidad produzca efectos debe ser declarada judicialmente a instancia de cualquier interesado en la exclusión del legatario o heredero indigno (art. 974 CC). Eso sí, en virtud del artículo 975 CC la indignidad se purga a los cinco

${ }^{21}$ En la doctrina chilena destaca la obra de los profesores Domínguez donde se analiza con detalle el principio sucesorio de la protección de la familia, vid. Domínguez R. y Domínguez R.; Derecho sucesorio, Editorial Jurídica de Chile, tomo I, 3ed, 2011, pp. 121-127.

${ }^{22}$ Este plazo de prescripción tiene lógica, ya que la acción por la que el legitimario puede reclamar la desheredación ilegal es la reforma del testamento y dicha acción tiene el plazo de prescripción mencionado. Luego si la acción de reforma ha prescrito, el legitimario ya no va poder reclamar su legítima con independencia de que este hubiera sido desheredado injustamente; Elorriaga de Bonis, F., op. cit., p. 491.

${ }^{23}$ Acerca de la interpretación de la ley y su potencial evolutiva vid. Betti, E.; La interpretación jurídica, LegalPublishing, Santiago, 2ed., 2009, pp. 105-108. 
años de posesión de la herencia o legado. No queda claro a qué posesión se refiere la ley. Al igual que Somarriva considero que tratándose de heredero bastaría con la posesión legal, ya que en ese momento el indigno adquiere la asignación. No sucedería lo mismo respecto del legatario, el que requeriría la posesión material de los bienes que constituyan el legado, debido a que respecto de él no existe la posesión legal ${ }^{24}$.

\section{La coexistencia de ambas instituciones}

Es posible afirmar, al igual que otros autores, que la indignidad y la desheredación son dos caminos distintos, uno legal y otro que parte de la voluntad del causante, que el ordenamiento ofrece para la consecución de un mismo fin ${ }^{25}$. Así Rodríguez Guez señala que con ciertos matices se puede afirmar que el desheredamiento es una indignidad testamentaria, mientras que la indignidad es un desheredamiento legal ${ }^{26}$. Son dos instituciones que apuntan en una misma dirección, esto es, excluir de la sucesión al asignatario que falta a su deber de lealtad y de respeto con el causante o con las personas que conforman su núcleo familiar más cercano.

A pesar de que el fin sea el mismo y, como vamos a ver a continuación, las causas sean semejantes, Elorriaga considera que la coexistencia de ambas instituciones en el sistema sucesorio chileno, lejos de ser una redundancia inútil, contribuye a la coherencia del sistema y confluye para la eficacia excluyente que se pretende ${ }^{27}$.

${ }^{24}$ Somarriva Undurraga, M.; Derecho sucesorio, tomo I, 6 ed., Editorial Jurídica de Chile, 2003, p. 116.

${ }^{25}$ Mena-Bernal Escobar, M.J.; La indignidad para suceder, Tirant Monografías, nº 39, Valencia, 1995, p. 275.

${ }^{26}$ Rodríguez-Grez, P.; Instituciones de Derecho sucesorio, vol. 2, Editorial Jurídica de Chile, Santiago, 2002, p. 47.

${ }^{27}$ De hecho, el paralelo de ambas instituciones también refleja diferencias significativas como por ejemplo que: a) las indignidades se refieren a cualquier asignación que pueda corresponder al indigno, sea forzosa o voluntaria; mientras que la desheredación solo se refiere a la asignación legítima; b) que la indignidad priva al asignatario de toda participación en la sucesión, pero no afecta a las donaciones que le haya hecho el causante, excepto al caso del artículo 1430 CC (prescripción de cuatro años de la acción de revocación de donaciones); mientras que la desheredación priva al asignatario de toda asignación en la sucesión y de las donaciones que le haya hecho el causante, salvo que este decida limitar los efectos de otra forma en la disposición testamentaria; c) que la indignidad declarada judicialmente no pasa a terceros de buena fe (art. $976 \mathrm{CC}$ ), mientras que el desheredamiento se rige por el artículo $1268 \mathrm{CC}$, pudiendo los herederos que sean llamados a la asignación del desheredado reivindicar aquello que no haya sido prescrito por un tercer poseedor; $y$, finalmente, d) el asignatario indigno está obligado a restituir la herencia o legado como sus accesiones y frutos, sin que se distinga entre poseedor de buena o mala fe (art. $974 \mathrm{CC}$ ); mientras que el asignatario desheredado se rige por el artículo 1267 CC que distingue entre poseedor de buena y mala fe, entendiendo esta referida al conocimiento o ignorancia del mismo desheredamiento contenido en el testamento.Vid. Elorriaga de Bonis, F.; op. cit., pp. 496-497. Queremos señalar al respecto que en otros países con larga tradición a favor de mantener la dualidad entre ambas instituciones como España, algunos autores se han mostrado favorables de lege ferenda a la unificación de ambas figuras, vid. García Rubio, M. P. y Otero Crespo, M., "Capacidad, Incapacidad e indignidad para suceder", en Tratado de Derecho de Sucesiones, tomo I, Thomson Reuters, Navarra, 2011, pp. 252-253. 


\section{Las causales de indignidad y desheredación}

Todas las causales de indignidad y desheredación reguladas contemplan conductas que se consideran reprobables de un heredero para con su causante.

Respecto de las causales de desheredación se establecen en el artículo 1208 CC, cuya enumeración es taxativa. La doctrina chilena afirma que no hay más causas de desheredamiento que las contempladas en el citado artículo, aun cuando la conducta que el heredero haya podido llevar a cabo pueda ser considerada más grave de las allí señaladas. Además por ser causales excepcionales y limitativas deben interpretarse restrictivamente, no admitiendo interpretaciones amplias o aplicaciones analógicas ${ }^{28}$.

Como se mencionó anteriormente, creo oportuno señalar que el hecho de que se exija una interpretación restrictiva de las causas taxativas no puede significar una exigencia tan estricta que impida cualquier tipo de interpretación de dichas causales. Respecto de la interpretación estricta y amplia de las disposiciones excepcionales, Larenz señala que "Se tiene que evitar que mediante una interpretación demasiado amplia de las disposiciones excepcionales o mediante su aplicación analógica la intención del legislador se trueque finalmente en lo contrario a ella. Pero esto no significa que la disposición excepcional haya de interpretarse tan estrictamente como sea posible o que la analogía quede excluida en todo caso. Aquí es decisiva de nuevo la razón por la que el legislador ha exceptuado precisamente esos casos" 29 . De acoger esta opinión, los jueces podrían interpretar las causales de desheredación adecuándose al tiempo y a la realidad social actual en la que se aplican, sin que ello se considerase una interpretación prohibida por su carácter extensivo. Eso sí, considero que contribuiría en mayor medida a la seguridad jurídica una solución de lege ferenda que consistiera en reformar dichas causales de desheredación contemplando un elenco expreso más completo y contemporáneo de las mismas, que incluyera alguna cláusula genérica que permitiera a los jueces encuadrar en ella varios hechos semejantes y ajustarse por esa vía a la realidad social de cada momento.

Por su parte las causales de indignidad se contienen en los artículos 968 a 972 CC. No obstante, dentro del Derecho de familia existen otras cinco causales de indignidad contempladas en los artículos 114, 124 y 127, 203, 994 y 219 CC. En el caso de la indignidad, a diferencia de la desheredación, no existe una disposición expresa que determine que estos supuestos regulados son los únicos por lo que un heredero podría ser declarado indigno. Sin embargo, la mayoría de la doctrina chilena entiende que no hay más causales de indignidad que las establecidas por la ley y que, por ello, quien las alega debe ceñirse a la descripción que para cada caso establece el Código Civil ${ }^{30}$.

En este punto discrepo y considero que en el ordenamiento chileno no es posible afirmar que existe un numerus clausus respecto de las causales de indignidad, a diferencia

\footnotetext{
${ }^{28}$ Elorriaga de Bonis, F.; op. cit., p. 489.

${ }^{29}$ Larenz, K., Metodología de la Ciencia del Derecho, Ariel Derecho, Barcelona, 2001, pp. 352-353.

${ }^{30}$ Elorriaga de Bonis, F.; op. cit., pp. 45-47, Somarriva Undurraga, M., op. cit., pp. 110-111 y RodríguezGrez, P., Instituciones de Derecho sucesorio, vol. I, Editorial Jurídica de Chile, 2002, p. 57.
} 
de lo que sucede con las causales de desheredación ${ }^{31}$. Si bien es cierto que la interpretación de las causales de indignidad debe ser restrictiva debido al efecto sancionador y limitativo de derechos que conllevan, también es oportuno tener presente que la ratio legis de estas normas no tiene solo en cuenta el aspecto punitivo, sino también la reprochabilidad social de ciertas conductas y la hipotética voluntad típica del causante medio en el caso de que dichas conductas acontezcan; es decir, cómo hubiera actuado presumiblemente un testador medio de acontecer dichas conductas ${ }^{32}$. Es por ello que a mi juicio sería oportuno privar de la herencia a aquel heredero que por su grave conducta sea desmerecedor de ello, aunque dicha conducta reprochable no se contemple expresamente en la norma. La ampliación de estas causas legales expresas quedaría dentro de la potestad judicial, pues el juez en su función interpretativa y aplicadora de la ley, podría declarar un determinado hecho no contemplado en la letra, pero sí en la ratio, como una causal de indignidad ${ }^{33}$.

No obstante, en materia de indignidad, al igual que sucedía con la desheredación, una posible solución de lege ferenda, que si bien no considero idónea podría aceptarse por la doctrina actual, sería explicitar en este caso la consideración de numerus clausus de las causales de indignidad; eso sí, de seguir esta línea argumental a mi juicio habría que contemplar un elenco expreso más completo y contemporáneo de esas casuales, que también incluyera una cláusula genérica que permitiera a los jueces encuadrar en ella varios hechos semejantes y ajustarse por esa vía a la realidad social de cada momento ${ }^{34}$.

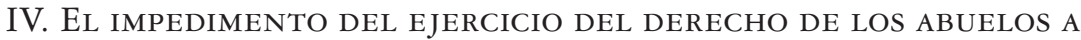 RELACIONARSE CON LOS NIETOS COMO CAUSA DE DESHEREDACIÓN}

Siguiendo con el argumento planteado, en Chile se ha llevado a cabo la reforma de Derecho de familia que contempla el derecho de los abuelos a relacionarse con sus

${ }^{31}$ En este punto sigo la doctrina española que tiende a la flexibilización de la aplicación de las causales de indignidad ampliando los supuestos de hecho que pueden provocarla, en este sentido, entre otros vid. Albadalejo García, M., Comentarios al Código civil, t. X, vol. 1º, Edersa, 1987, p. 209 y Coca Payerás, M., "Indignidad par suceder", voz Enciclopedia Jurídica Básica, vol. III, Civitas, 1995, pp. 3532-3533.

32 Considero que la delación legal a la sucesión intestada es una ficción jurídica sobre la hipotética voluntad típica de un causante medio, ya que no se trata de una presunción de voluntad del causante en un caso concreto, sino de una abstracción de la que sería la voluntad del hombre medio a la hora de realizar el llamamiento a su sucesión. El legislador sobre la base de dicha hipotética voluntad típica de un causante medio establece unos llamamientos determinados a la sucesión intestada que, en ausencia de disposición expresa en contrario, tendrán que ser respetados con independencia de que en el caso concreto no respondan a los afectos reales de un causante en particular; vid. Espada Mallorquín, S., Los derechos sucesorios de las parejas de hecho, Thomson-Civitas, 2007, Madrid, pp. 326-327.

33 En el mismo sentido Mena-Bernal Escobar, M.J., op. cit., pp. 65-66.

${ }^{34}$ En este sentido se han llevado a cabo reformas en otros ordenamientos, así en el Derecho francés existe la llamada indignidad facultativa, donde es el juez el que en última instancia y conforme a los hechos decide la aplicación de la causal; o el Código civil de Cataluña donde se han ampliado los supuestos de hecho que pueden ser causal de indignidad teniendo en cuenta la jurisprudencia y la realidad social y familiar actual, vid. García Rubio, M. P. y Otero Crespo, M., op. cit., p. 251. 
nietos. Si como hemos precisado este reconocimiento parte de la importancia de garantizar el desarrollo de los vínculos de afectividad intergeneracionales y el fundamento de la desheredación es que el testador pueda privar de los derechos legitimarios a aquellos que desarrollen conductas reprochables contra los familiares más próximos, considero que lo más oportuno hubiera sido que el legislador realizara una reforma en el ámbito del Derecho sucesorio que contemplase la vulneración del derecho de los abuelos como una causal legítima de desheredación de los progenitores incumplidores.

El fundamento de esta nueva casual se encontraría en que el impedimento injustificado del ejercicio del derecho de los abuelos por parte del descendiente o del ascendiente supondría una violación grave o una conducta contraria con los lazos familiares cercanos que le unen con el causante, que pondría en cuestionamiento el respeto hacia el mismo y con ello la justificación de su asignación legal, lo que abriría la posibilidad de su justa desheredación por parte del causante.

Por tanto, de lege ferenda hubiera sido oportuna la inclusión de dicha causa de forma expresa dentro del ordenamiento. De incluirse, tanto el abuelo podría desheredar al hijo que le impide mantener una relación directa y regular con sus nietos como el nieto mayor de catorce años (arts. 1005 y 26 CC) podría desheredar al padre que le impidiese relacionarse con sus abuelos. Eso sí, como se explicará más ampliamente a continuación, en ambos casos debiera exigirse como requisito la existencia de una sentencia donde se fijara el régimen de relación directa y regular entre los abuelos y nietos, cuyo cumplimiento se ve impedido por el desheredado.

Más allá de la reforma legislativa, en la actualidad también abogaría por buscar una solución de lege lata. Para ello partiría de la premisa de que si bien es cierto que las causas de desheredación son taxativas y la interpretación de las mismas ha de ser estricta, esto no significa que ningún tipo de interpretación jurídica pueda ser posible dentro de ellas. En este sentido, el juez dentro de su función interpretativa y aplicadora de la ley, podría declarar que el impedimento del ejercicio del citado derecho de los abuelos si bien no está contemplado en la letra, sí lo está en la ratio legis de la desheredación. En este caso concreto considero que estaría dentro de la causal más genérica relativa a la injuria grave (art. $1208.1^{\circ} \mathrm{CC}$ ).

Respecto de la injuria grave, en el artículo $1208.1^{\circ} \mathrm{CC}$ se contempla como causal justa de desheredación el haber cometido el legitimario injuria grave contra el testador en su persona, honor o bienes, o en la persona, honor o bienes del cónyuge o de cualquier otro ascendiente o descendiente. Lo que se considera una injuria grave no se encuentra ni descrito ni definido en la ley. La doctrina considera que el término injuria grave no puede tomarse con una significación penal (art. 416 C. Penal), sino con un significado más genérico que hace referencia a daño o perjuicio, como se define en el artículo 44 $\mathrm{CC}^{35}$. Según el citado precepto la culpa grave en el ámbito civil equivale al dolo y este consiste en la intención positiva de inferir injuria a la persona o propiedad de otro. Por tanto es posible interpretar que podrá ser desheredado quien haya cometido injuria en

${ }^{35}$ Elorriaga de Bonis, F.; op. cit., p. 492. 
el sentido de grave daño o menoscabo intencional en contra de alguna de las personas que se mencionan en el artículo $1208.1^{\circ} \mathrm{CC}$.

En la actualidad, la determinación de si existe un daño y la gravedad del mismo es una cuestión de hecho que deberá ser apreciada por los tribunales del fondo. En este sentido entiendo que el impedimento injustificado por parte de un hijo a que los abuelos mantengan una relación directa y regular con los nietos tras el reconocimiento jurídico mediante sentencia puede calificarse como un daño grave. La gravedad del daño deriva del carácter irreparable del mismo, al privar al menor del mantenimiento de lazos afectivos intergeneracionales que le resultan beneficiosos para su normal desarrollo y formación de la personalidad y, también priva a los abuelos de la posibilidad de cohesión y transmisión de valores en la familia; todo ello, claro está, será un daño grave si dicha privación es injusta, pero no cuando el ejercicio de dicho derecho pudiera resultar perjudicial para el menor.

Además el impedimento al ejercicio del derecho también resulta grave porque dicho comportamiento por parte del hijo supone un incumplimiento del deber de respeto de los hijos respecto de los padres (art. 222.1 ${ }^{\circ} \mathrm{CC}$ ). Entiendo este deber de respeto como la atención, consideración y deferencia que los hijos deben a los padres, reconociéndoles su valor propio y el de sus derechos. De ser así que un hijo impida al padre el ejercicio legítimo de su derecho a mantener una relación directa y regular con sus nietos supondría, a mi juicio, una falta al citado deber de respeto.

Por todo ello, entiendo que impedir el desarrollo normal de la relación directa y regular entre los abuelos y los nietos puede suponer un daño grave para los abuelos y para los nietos. De hecho, en otros ordenamientos, esa privación puede llegar a constituir lo que se ha denominado un caso de maltrato afectivo o emocional por parte del hijo que legitima una sanción tan importante como la desheredación del legitimario que impide esa relación ${ }^{36}$.

Es claro que para que constituya un daño grave necesariamente la relación hostil entre los ascendientes y los legitimarios no debería de ser recíproca, en el sentido de que la indiferencia y el distanciamiento con los nietos no sea solo producto del impedimento paterno, sino de la falta de interés por parte de los abuelos. En este último caso no podríamos hablar de daño grave o injuria. Eso sí, le correspondería al desheredado probar el desinterés recíproco del abuelo tras la respectiva sentencia judicial que establece el ejercicio de la relación directa y regular con los nietos; lo que de acreditarse

36 Barceló Doménech pone de manifiesto cómo dentro de la jurisprudencia española se tiende a no entrar a valorar las circunstancias concretas que rodean las relaciones entre padres e hijos; pero lo cierto es que como señala esta autora para poder interpretar correctamente si existen malos tratos graves psíquicos que justifiquen la causal de desheredación es necesario valorar dichas relaciones para comprobar si existen actos de desprecio, de burla, de ausencia de interés, de no permitir la relación con los nietos o incluso la inasistencia a la última enfermedad o al entierro; ya que si con dichos actos y sin mediar culpa del causante se le ha provocado sufrimiento, existe la posibilidad de considerarlos un mal trato psíquico que sea subsumible en el artículo 853.2 CC español; vid. Barceló Doménech, J., "La desheredación de los hijos y descendientes por maltrato de obra o injurias graves de palabra", en Revista Crítica de Derecho Inmobiliario, 2004, pp. 509-510. 
podría constituir el fundamento para considerar injusta la desheredación efectuada por no poder calificarse su comportamiento como injuria grave.

Para que podamos hablar de una causa de desheredación legítima tiene que existir un efectivo impedimento al ejercicio del derecho de relación directa y regular del testador que quiere ejercitarlo y se ve impedido sin justa causa a hacerlo. Por ello para que se aplique esta interpretación de la causal de desheredación es imprescindible la existencia de una sentencia donde se establezca el derecho de relación directa y regular del abuelo. Solo la constatación de la injusticia del impedimento del ejercicio del derecho por parte del hijo tras la sentencia judicial, permitiría que su conducta fuera susceptible de ser calificada como una injuria grave por producir intencionadamente un menoscabo al titular del derecho.

Esto permite plantearse varias hipótesis. En primer lugar puede suceder que el hijo niegue injustificadamente al abuelo el mantenimiento de esta relación directa y regular con su nieto no llegando a acuerdos y que judicialmente el abuelo solicite al juez que fije la modalidad de esta relación y el juez se la conceda. En este caso habría que separar la pretensión de Derecho de familia de tener efectivamente la relación directa y regular con el nieto que se ha visto satisfecha por vía judicial, con la posibilidad de desheredación del hijo. Si se dicta una sentencia donde se fija el régimen de relación directa y regular de los abuelos, entiendo que la desheredación sería posible, si tras esta sentencia el hijo impide el ejercicio del derecho a la relación directa y regular reconocido judicialmente, pero también si cumple posteriormente con la sentencia, ya que la conducta del hijo fue reprochable para con el padre, constituyendo una injuria grave, que salvo perdón, justificaría su desheredación. Eso sí, si el afectado por la desheredación rechaza los motivos de la misma por considerarla injusta, deberá ser un juez el que en sentencia judicial ejecutoriada tenga por acreditada tanto la causal y califique su comportamiento como injuria grave para que la desheredación fuera efectiva ${ }^{37}$.

Otra hipótesis sería que el hijo se negara a dicha relación del abuelo con el nieto y que en el proceso para fijar judicialmente la relación directa y regular del abuelo se determinase que en interés del nieto dicha relación es mejor que no se lleve a cabo por perjudicar el bienestar del menor. En ese supuesto entiendo que no cabría que el abuelo desheredase al hijo por impedirle dicha relación, ya que dicho impedimento estaría justificado por la sentencia judicial. El comportamiento del hijo no sería una injuria grave hacia el padre sino el cumplimiento de un límite legítimo al ejercicio del derecho del abuelo. No se daría un caso de injuria, pues el impedimento al ejercicio del derecho de relación directa y regular estaría amparado por la protección del interés superior del menor.

Finalmente, también puede suceder que el abuelo se vea impedido injustificadamente para ejercitar su derecho, pero que para no judicializar el conflicto familiar decida no acudir a los tribunales. Cuando el abuelo decide no acudir a la vía judicial, pero a pesar de ello deshereda al hijo por esa conducta, entiendo que no sería posible que el juez

${ }^{37}$ Rodríguez-Grez, P.; op. cit., vol. 2, pp. 22-23. 
considerase que se trata de una justa desheredación del hijo por su parte. Existiría un evidente problema de prueba, ya que al no dictarse una sentencia no es posible afirmar que dicho impedimento del ejercicio sea injustificado, pues es admisible la posibilidad de que el impedimento del ejercicio del derecho venga motivado por la protección del interés superior del menor. Debido a la gravedad que implica reconocer la legitimidad de la causal de desheredación es necesario que la gravedad de la conducta reprochable esté debidamente acreditada y para ello sería necesaria la existencia de la sentencia judicial.

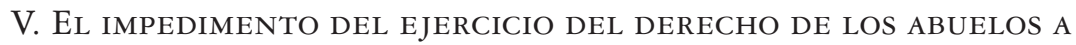 RELACIONARSE CON LOS NIETOS COMO CAUSA DE INDIGNIDAD}

La mayor parte de la doctrina chilena considera que las causales de indignidad son taxativas. De seguir esta tesis de forma estricta, en el sentido de no admitir ningún tipo de interpretación amplia y en línea con la idea de dotar de una mayor seguridad jurídica al sistema, la única vía posible que permitiría aceptar que el impedimento del ejercicio de este deber es una casual de indignidad sería que se llevase a cabo una reforma legislativa donde se contemplase de forma expresa como causal de indignidad el impedimento injustificado al ejercicio del derecho a mantener una relación directa y regular entre abuelos y nietos. De seguir esta línea interpretativa, el contenido de la citada norma podría ser que tras el fallecimiento del causante, probada la existencia de una sentencia judicial que atribuyese un régimen de relación directa y regular entre abuelos y nietos, que hubiera constatado el impedimento injustificado de su ejercicio por parte del posible heredero testamentario o legal, se le podría sancionar civilmente con su consideración como indigno y, por ello, salvo que se pruebe su perdón (art. 973 CC), no tendría derecho a sucederle.

En ausencia de dicha norma expresa, considero oportuno plantear de lege data dos posibles interpretaciones en el ámbito sucesorio tras la reforma de Derecho de familia.

Una primera posibilidad es sostener, como se argumentó anteriormente, que las casuales de indignidad en el ordenamiento chileno no constituyen en realidad un $n u$ merus clausus. De ser así el juez teniendo en cuenta que la ratio legis de las causales de indignidad es la reprochabilidad social de ciertas conductas junto con la hipotética voluntad típica del causante medio, podría privar de la herencia a aquel heredero que por su grave conducta sea desmerecedor de ello, aunque dicha conducta reprochable no se contemple expresamente como casual de indignidad ${ }^{38}$.

De admitirse esta premisa entiendo que si el abuelo se ve obligado a acudir a la justicia para que se fije un régimen de relación directa y regular con sus nietos para tener la posibilidad de relacionarse con ellos y una sentencia se lo reconoce, el juez

${ }^{38}$ Esta idea es la que subyace dentro del ámbito comparado en la Forteiture rule del Common Law donde a pesar de no existir la figura de la indignidad se considera radicalmente inmoral que quien comente actos muy graves contra el causante (responsable de su muerte) pueda llegar a beneficiarse de su sucesión, vid. García Rubio, M. P. y Otero Crespo, M., op. cit., pp. 248-249 y 251. 
podría declarar que el hijo es indigno de suceder a los padres. Esta conducta del heredero sería un hecho socialmente repudiable contra el causante, un comportamiento desleal hacia el fallecido, que le haría indigno de sucederle, ya que existe un sentimiento de reprochabilidad social que implica que quien comete ciertos actos muy graves contra el causante, en este caso impedirle injustificadamente el derecho a relacionarse con su nieto, no es legítimo que se beneficie de la sucesión del mismo.

Otra posible interpretación es sostener que las causales de indignidad reguladas en el Código Civil son taxativas. En ese caso también sería posible considerar en la actualidad que el impedimento al ejercicio del deber de relación directa y regular entre abuelos y nietos es una causa de indignidad. Esto implicaría afirmar que si bien la labor interpretativa del juez de las causales de indignidad debe ser restrictiva a causa del efecto sancionador y limitativo de derechos que conllevan, esto no implica perder de vista que también debe tenerse presente la ratio legis de estas normas consistente en la reprochabilidad social de ciertas conductas y su influencia en la hipotética voluntad típica del causante medio.

De seguir esta argumentación, dentro de las casuales de indignidad contempladas en el ordenamiento chileno se podría acudir al artículo $968.2^{\circ} \mathrm{CC}$ que establece la indignidad para suceder al fallecido de aquel que cometa un atentado grave contra la vida, el honor o los bienes del causante, del cónyuge o de cualquier ascendiente o descendiente, con tal de que dicho atentado se pruebe por sentencia ejecutoriada. En este sentido, el impedimento injustificado del ejercicio del derecho de relación directa y regular entre abuelos y nietos podría constituir un atentado grave contra la vida del causante. Veamos en qué sentido.

Esta interpretación del contenido del artículo $968.2^{\circ} \mathrm{CC}$ conforme a la ratio de la norma, implicaría las siguientes premisas interpretativas. En primer lugar, a diferencia de Somarriva ${ }^{39}$, considero que cuando se hace mención en el citado artículo a la necesidad de sentencia ejecutoriada esto no implica necesariamente que dicha sentencia tenga que ser criminal condenatoria. De interpretarse en este sentido la norma, el juez civil encargado de declarar la indignidad tendría una nula capacidad de apreciación acerca de la conducta del indigno respecto de esta casual de indignidad ${ }^{40}$. Siguiendo a la doctrina italiana y alemana en esta materia, entiendo que la necesidad de sentencia por esos atentados graves no debe interpretarse en un sentido estrictamente penal, sino en el sentido natural de existencia de un proceso condenatorio ${ }^{41}$. En el caso que estamos analizando, este requisito se cumpliría si existiera una sentencia judicial que determinase el régimen del ejercicio de la relación directa y regular por parte del causante.

Para poder aplicar esta causal sí que sería precisa la existencia de una sentencia donde el juez de familia hubiera fijado el ejercicio de la relación directa y regular de los abuelos y nietos con oposición injustificada del hijo, para que el hijo pudiera ser

\footnotetext{
${ }^{39}$ Somarriva Undurraga, M.; op. cit., pp. 110-111.

${ }^{40}$ García Rubio, M. P. y Otero Crespo, M., op. cit., p. 255.

${ }^{41}$ Monosi, S., "L'indignità a succedere", en Tratado breve delle Successioni e Donazioni, vol. I, Cedam, Padova, 2010, p. 210 y Frank, R., Erbrercht, Verlang, München, 2007, pp. 278-279.
} 
declarado indigno de suceder al causante al haber cometido un atentado grave contra el fallecido. Por tanto, en estos casos, si el causante no hubiera solicitado judicialmente el ejercicio del derecho a la relación directa y regular con su nieto, al igual que se planteó respecto de la desheredación, por más que la conducta reprochable por parte del hijo fuera notoria en los hechos, no podría considerarse indigno al hijo que hubiera impedido el ejercicio de dicho derecho en ausencia de una sentencia judicial que determinase dicho impedimento como injustificado teniendo en cuenta el interés del menor.

En segundo lugar, entiendo que este comportamiento del hijo es subsumible en la causal de indignidad del artículo $968.2^{\circ} \mathrm{CC}$, porque considero admisible interpretar en el citado artículo el término atentado grave como sinónimo de injuria atroz, es decir, daño o perjuicio grave ${ }^{42}$. A la hora de determinar qué significa un atentado grave contra la vida del causante, no solo cabría entender que se refiere a supuestos de homicidio o asesinato sino que también se incluyen lesiones graves o maltratos que pueden ser de índole psicológica ${ }^{43}$. De ser así, de nuevo es factible argumentar que la negativa injustificada a la relación directa y regular de los abuelos con los nietos constituye un maltrato emocional o afectivo que no solo vulnera el derecho legalmente reconocido, sino que igualmente violenta el deber de respeto de los hijos con sus ascendientes (art. 222.1 ${ }^{\circ} \mathrm{CC}$ ).

De admitirse esta línea argumental sería oportuno interpretar que el impedimento injustificado del ejercicio del derecho a una relación entre abuelos y nietos por parte de un heredero establecido judicialmente es una causa de indignidad por implicar en un sentido amplio un atentado grave contra la vida del causante que justifica que se prive al heredero de la herencia. Es decir, en estos casos sería necesario acreditar tanto la existencia de una sentencia que establece un régimen de relación directa y regular del abuelo, como el impedimento posterior del ejercicio del mismo de forma que constituya un atentado grave por parte del heredero contra el causante. De seguirse esta argumentación, el juez, dentro de su función interpretativa y aplicadora de la ley, podría interpretar la casual del artículo $968.2^{\circ}$ CC conforme a la ratio del precepto: evitar que el heredero causante de un maltrato afectivo acreditado al fallecido pueda verse beneficiado con su herencia.

\section{BIBLIOGRAFÍA}

Albadalejo García, M.; Comentarios al Código civil, t. X, vol. 1º, Edersa, 1987.

Algaba Ros, S.; Efectos de la desheredación, Tirant monografías, Valencia, 2002.

Barceló Doménech, J., "La desheredación de los hijos y descendientes por maltrato de obra o injurias graves de palabra”, en Revista Crítica de Derecho Inmobiliario, 2004, pp. 473-520.

\footnotetext{
42 Sobre esta interpretación de atentado grave, vid. Elorriaga de Bonis, F.; op. cit., p. 492.

${ }^{43}$ En este sentido dentro de la doctrina española se interpreta que el maltrato de obra no se limita a la violencia física, sino que también contempla el maltrato afectivo o emocional, vid. Torres García, T. y Domínguez Luelmo, A. "La legítima en el Código Civil”, en Tratado de Derecho de sucesiones, tomo II, Thomson Reuters, Navarra, 2011, pp. 1890-1891.
} 
Berrocal Lanzarot, A. I.; "Derecho de visitas de los abuelos. A propósito de la STS de 20 de octubre de 2011", en Revista Crítica de Derecho Inmobiliario, nº 730, pp. 987-1198.

BetTi, E.; La interpretación jurídica, Legal Publishing, Santiago, 2ed., 2009.

Carballo Fidalgo, M.; "El derecho de visita de los abuelos y la atribución de guarda de sus nietos tras la Ley 42/2003, de 21 de noviembre. Aspectos sustantivos y procesales", en Revista de Derecho de Familia, no 30, enero-marzo 2006, Madrid, pp. 45-77

Coca Payerás, M., "Indignidad par suceder", voz Enciclopedia Jurídica Básica, vol. III, Civitas, 1995 , pp. 3532-3533.

ColÁs Escadón, A.; Relaciones familiares de los nietos con los abuelos: derecho de visitas, estancia, comunicación y atribución de guarda y custodia (Ley 42/2003), Thomson Aranzadi, Navarra, 2005.

De Prada González, J. M.; "La patria potestad tras la reforma del Código Civil", en Anales de la Academia Matritense y del Notariado, t. XXV, 1982, Madrid, pp. 389 y ss.

DíAz Alabart, S.; "El derecho de relación personal del menor y sus parientes y allegados (art. 160.2 CC)", en Revista de Derecho Privado, mayo-junio 2003, pp. 353 y ss.

Domínguez Benavente R. y Domínguez Águila, R., Derecho sucesorio, Editorial Jurídica de Chile, tomo I, 3ed., Santiago, 2011.

Elorriaga de Bonis, F., Derecho Sucesorio, Abeledo Perrot, Santiago, 2010.

EsPada Mallorquín, S., Los derechos sucesorios de las parejas de hecho, Thomson-Civitas, Madrid, 2007.

Frank, R., Erbrercht, Verlang, München, 2007.

GARCía Ibáñez, J. "El derecho a las relaciones personales entre nietos y abuelos. Una aproximación sociojurídica”, en REDUR 10, diciembre 2012, pp. 105-122.

García Rubio, M. P. y Otero Crespo, M., "Capacidad, Incapacidad e indignidad para suceder", en Tratado de Derecho de Sucesiones, tomo I, Thomson Reuters, Navarra, 2011, pp. 225-273.

GAYA Sicilia, R.; "El derecho de los abuelos a relacionarse con los nietos"; en Anuario de Derecho civil, 2002-I, Madrid, pp. 96 y ss.

KaIl Robert V. y Cavanaugh John C., Desarrollo bumano. Una perspectiva del ciclo vital, 5 ed., Cengage Learning, México, 2011.

Larenz, K., Metodología de la Ciencia del Derecho, Ariel Derecho, Barcelona, 2001.

Lete del Río, J. M.; "El derecho de visitas de los abuelos”, en Poder Judicial, nº 25, marzo 1992, pp. 149 y ss.

Mena-Bernal Escobar, M.J.; La indignidad para suceder, Tirant Monografías, n³ 39, Valencia, 1995.

Monosi, S., "L'indignità a succedere", en Tratado breve delle Successioni e Donazioni, vol. I, Cedam, Padova, 2010, pp. 195 y ss.

RodríGuez Grez, P., Instituciones de Derecho Sucesorio, vols. 1 y 2, Editorial Jurídica de Chile, Santiago, 2002.

Ruz Lártiga, G.; "El Derecho de visitas en Francia: un derecho de la persona en la búsqueda del justo equilibrio entre Derecho parental, interés del niño y prerrogativas de terceros", en Revista Chilena de Derecho de Familia, no 3, Santiago, 2010, pp. 139-162.

Salanova Villanueva, M. "Notas sobre el der echo de los abuelos a mantener relaciones personales con sus nietos", en Anuario de Derecho civil, 1996-I, pp. 952 y ss.

Somarriva Undurraga, M.; Derecho sucesorio, tomo I, 6 ed., Editorial Jurídica de Chile, 2003.

Torres García, T. y Domínguez Luelmo, A. "La legítima en el Código Civil”, en Tratado de Derecho de sucesiones, tomo II, Thomson Reuters, Navarra, 2011, pp. 767-834. 
